\title{
Surgical outcomes of infective endocarditis among intravenous drug users
}

\author{
Joon Bum Kim, MD, PhD, ${ }^{\mathrm{a}, \mathrm{d}}$ Julius I. Ejiofor, MD, ${ }^{\mathrm{b}}$ Maroun Yammine, MD, ${ }^{\mathrm{b}}$ Masahiko Ando, MD, ${ }^{\mathrm{a}}$ \\ Janice M. Camuso, RN, ${ }^{a}$ Ilan Youngster, MD, ${ }^{c}$ Sandra B. Nelson, MD ${ }^{c}$ Arthur Y. Kim, MD, \\ Serguei I. Melnitchouk, MD, ${ }^{\mathrm{a}}$ James D. Rawn, MD, ${ }^{\mathrm{b}}$ Thomas E. MacGillivray, MD, ${ }^{\mathrm{a}}$ \\ Lawrence H. Cohn, MD, ${ }^{b}$ John G. Byrne, MD, ${ }^{b}$ and Thoralf M. Sundt III, MD
}

\begin{abstract}
Background: With increasing prevalence of injected drug use in the United States, a growing number of intravenous drug users (IVDUs) are at risk for infective endocarditis (IE) that may require surgical intervention; however, few data exist about clinical outcomes of these individuals.

Methods: We evaluated consecutive adult patients undergoing surgery for active IE between 2002 and 2014 pooled from 2 prospective institutional databases. Death and valve-related events, including reinfection or heart valve reoperation, thromboembolism, and anticoagulation-related hemorrhage were evaluated.
\end{abstract}

Results: Of the 436 patients identified, 78 (17.9\%) were current IVDUs. The proportion of IVDUs increased from $14.8 \%$ in 2002 to 2004 to $26.1 \%$ in 2012 to 2014. IVDUs were younger (aged $35.9 \pm 9.9$ years vs $59.3 \pm 14.1$ years) and had fewer cardiovascular risk factors than non-IVDUs. During follow-up (median, 29.4 months; quartile 1-3, 4.7-72.6 months), adverse events among all patients included death in 92 , reinfection in 42 , valve-reoperation in 35 , thromboembolism in 17 , and hemorrhage in 16 . Operative mortality was lower among IVDUs (odds ratio, 0.25; 95\% confidence interval [CI], 0.06-0.71), but overall mortality was not significantly different (hazard ratio [HR], $0.78 ; 95 \%$ CI, 0.44-1.37). When baseline profiles were adjusted by propensity score, IVDUs had higher risk of valve-related complications (HR, 3.82; 95\% CI, 1.95-7.49; $P<.001)$ principally attributable to higher rates of reinfection (HR, 6.20;95\% CI, 2.56-15.00; $P<.001)$.

Conclusions: The proportion of IVDUs among surgically treated IE patients is increasing. Although IVDUs have lower operative risk, long-term outcomes are compromised by reinfection. (J Thorac Cardiovasc Surg 2016;152:832-41)

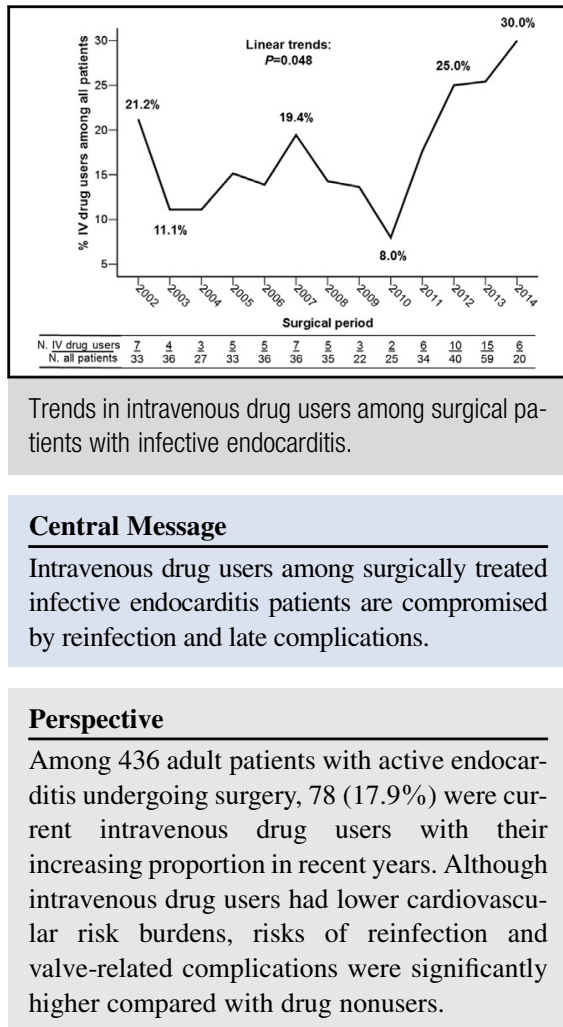

See Article page 677.

See Editorial Commentaries page 681 and 842 .
From the Divisions of a Cardiac Surgery and ${ }^{\mathrm{c}}$ Infectious Disease, Massachusetts General Hospital and 'Division of Cardiac Surgery, Brigham and Women's Hospital, Harvard Medical School, Boston, Mass; and ${ }^{\mathrm{d}}$ Department of Thoracic and Cardiovascular Surgery, Asan Medical Center, University of Ulsan College of Medicine, Seoul, South Korea.

J.B.K. was sponsored by the AATS Graham Memorial Fellowship for this research.

J.B.K. and J.I.E. contributed equally to this article.

Read at the 95th Annual Meeting of The American Association for Thoracic Surgery, Seattle, Washington, April 25-29, 2015.

Received for publication Oct 12, 2015; revisions received Jan 24, 2016; accepted for publication Feb 14, 2016; available ahead of print April 8, 2016.

Address for reprints: Thoralf M. Sundt III, MD, Division of Cardiac Surgery, Massachusetts General Hospital, Cox 652, 55 Fruit St, Boston, MA 02114 (E-mail: tsundt@partners.org).

$0022-5223 / \$ 36.00$

Copyright (c) 2016 by The American Association for Thoracic Surgery

http://dx.doi.org/10.1016/j.jtcvs.2016.02.072
Intravenous drug abuse is increasing rapidly in the United States. Use of heroin, the most common illicit injected drug worldwide, almost doubled in the United States between 2006 and 2013 to 681,000 active users,

Scanning this QR code will take you to supplemental figure for this article. To view the AATS 2015 Webcast, see the URL at the end of the article.

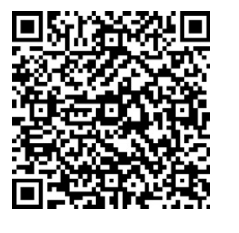



Abbreviations and Acronyms
$\mathrm{BWH}=$ Brigham and Women's Hospital
IE $=$ infective endocarditis
IVDU $=$ intravenous drug user
IV $=$ intravenous
MGH $=$ Massachusetts General Hospital
STS $=$ Society of Thoracic Surgeons

with an estimated 169,000 people starting the drug in 2013. ${ }^{1}$ The majority of intravenous drug users (IVDUs) are young adults who find heroin less expensive and easier to obtain than prescription opioids. ${ }^{1-3}$ The incidence of heroin-related deaths has surged during this same period as well, with nearly 6000 deaths recognized to be caused by heroin intoxication in 2013, a figure almost tripled from that of $2006 .^{4}$ Consequently, this has become a major public health issue in the United States.

Of the many medical complications of drug abuse, infective endocarditis (IE) is particularly challenging given the significant risk of acute mortality as well as social factors such as late recidivism and reinfection. Overall, IE carries in-hospital and 1-year mortality rates of $10 \%$ to $20 \%$ and a nearly $40 \%$, respectively, even in the current era. ${ }^{5,6}$ Of those with IE, $60 \%$ to $70 \%$ will ultimately require heart valve surgery, particularly those with resistant or highly virulent organisms as is common among intravenous (IV) drug use-associated IE. ${ }^{5-8}$ The decision to proceed with surgical treatment is further complicated among IVDUs because reinfection of a prosthetic valve increases subsequent operative risk and diminishes the likelihood of medical cure. ${ }^{9-12}$ Given an estimated incidence of IE among this population of 100 to 400 per 100,000 personyears, which is 50 to 100 times that of the population at large, and the increased prevalence of IV drug use in the United States, this is likely to be an increasingly common clinical conundrum. ${ }^{6,7,13-15}$

Enthusiasm for operative management of IE in IVDUs in the surgical community is mixed, given anecdotal experience of repeated recurrences attributable to continued use of IV drugs. ${ }^{16}$ Furthermore, independent of reinfection, survival of IVDUs is threatened by competing causes of mortality, including drug intoxication, trauma, and suicide. $^{8,17-19}$ These issues raise questions about the utility versus futility of aggressive, resource-intensive surgical procedures, particularly among patients who are actively injecting drugs. ${ }^{16,20}$ There are limited data concerning the clinical characteristics and prognosis after surgical therapy of these patients to inform clinical decision making and postoperative care. ${ }^{17,21}$ We therefore sought to examine short- and long-term outcomes in the surgical management of IE among patients who are IVDUs in comparison to non-IVDUs associated with IE. In the interest of capturing an adequately sized cohort, data were pooled from 2 closely associated tertiary academic centers in Boston, Massachusetts.

\section{METHODS}

\section{Study Population and Outcome Measures}

The prospectively collected cardiac surgery databases of the Massachusetts General Hospital (MGH) and the Brigham and Women's Hospital (BWH) were queried to identify patients aged 17 years or older undergoing heart valve operations due to active IE from January 2002 through August 2014. The disease was considered active according to the Society of Thoracic Surgeons (STS) definitions if the patient was currently being treated for endocarditis. ${ }^{22}$ These 2 databases uniformly record baseline patient characteristics, information on cardiac surgical procedures, and perioperative outcomes according to STS definitions. In addition, retrospective chart reviews were conducted to collect detailed information regarding IV drug use status and profiles on IE such as specific pathogens, characteristics of valvular lesions, and treatment details. IVDUs currently engaging in IV drug use were defined as those who had injected drugs during the past 12 months as suggested by prior studies. ${ }^{1,4,23}$

Follow-up information on individual patients was obtained through January 2015 by review of longitudinal data from Partners Health Care System, the largest health care system in Massachusetts, which maintains a centralized clinical data registry of all patient encounters within the system, including BWH and MGH. ${ }^{19}$ This data warehouse has been used for other clinical research and its coding data have been validated in several prior studies. $^{24-26}$

The primary outcome of interest was death and valve-related complications, the latter including reinfection or reoperation of the heart valves, thromboembolic events, and anticoagulation-related hemorrhage as defined by STS. ${ }^{27}$ Early mortality was defined as those occurring in-hospital or within 30 days of surgery. The diagnosis of valvular reinfection was based on 1 of the following criteria as suggested by STS guidelines: findings on reoperation with evidence of abscess, paravalvular leak, frank pus, or vegetation confirmed as secondary to infection by histologic or bacteriologic studies; or meeting of the Duke Criteria for endocarditis in the absence of reoperation. ${ }^{27}$ Thromboembolic complications, including neurologic (stroke or transient ischemic attack) or peripheral embolic events producing signs or symptoms caused by the obstruction of a peripheral artery, were diagnosed clinically. Diagnosis of septic pulmonary embolism was made by the findings on enhanced computed tomography scan of the chest when clinically suspected, particularly in cases with IE involving rightsided heart valve. Anticoagulation-related hemorrhage was defined as requiring transfusion, unplanned hospital admission, or a hemostatic intervention. ${ }^{27}$ Early-, intermediate- and late-onset of recurrent IE were defined as those that occurred within 30 days, between 30 and 360 days, and beyond 360 days of surgery based on the current practice guidelines. ${ }^{7}$

The study protocol was approved by the Institutional Review Board of Partners Healthcare, which encompasses the MGH and the BWH. The requirement for informed consent from individual patients was waved due to the retrospective nature of the study design.

\section{Statistical Analysis}

Categorical variables, presented as frequencies and percentages, were compared using the $\chi^{2}$ test or Fisher exact test. Continuous variables, expressed as mean \pm standard deviation or median with range (or quartile 1-3), were compared using the Student unpaired $t$ test or the Mann-Whitney $U$ test. Annual trends in proportions of IVDUs among surgical patients with infective endocarditis were tested by $\chi^{2}$ test for linearity. Kaplan-Meier curves were used to plot the survival and freedom from adverse events. 
Log-rank tests were used to compare the differences in the time-related outcomes between groups. Given the significant differences in demographic and clinical risk profiles between the 2 groups of patients in favor of the IVDU group, we assumed that relative risks of deaths may differ across early and late postoperative periods. To address this issue, landmark mortality analyses were performed split into 2 intervals: 90 days or less and more than 90 days following surgery. ${ }^{28}$ To adjust for baseline risk profiles between IVDUs and non-IVDUs in the evaluations of outcomes, we performed propensity score analysis. The propensity scores were calculated by multiple logistic regression analysis that included baseline variables shown in Tables 1 and 2. Model discrimination and calibration were evaluated with the $\mathrm{C}$ statistics $(\mathrm{C}=0.936)$ and Hosmer-Lemeshow statistics $(P=.275)$, respectively. Propensity score matching yielded only 33 pairs of patients; therefore, we conducted a covariate adjustment with propensity score rather than using the propensity score as a matching tool. With this technique, propensity scores were incorporated into Cox proportional hazard models as a covariate as well as IV drug use status to calculate the propensity-adjusted hazard ratio (HR). Cox-proportional hazard models were used with robust standard errors that accounted for the clustering by center. The proportional hazards assumption was confirmed by examination of $\log (-\log [$ survival $])$ curves and by testing of partial (Schoenfeld) residuals and no relevant violations were found.

Because defining IV drug use depended heavily on patients' own reports, we assumed that there was potential uncertainty in classifying IV drug use status. To account for potential influence of underestimation of current IV drug use, a sensitivity analysis was performed. For this analysis, we randomly sampled $3 \%$ of patients in the non-IVDU group to reclassify them as IVDUs and recalculated HRs for clinical end points. This procedure was repeated for 100 times to obtain averaged HRs and $95 \%$ confidence intervals (CIs). We gradually increased the proportions of reclassified patients from $3 \%$ to $70 \%$ of all non-IVDUs, and evaluated how this reclassification influenced overall HRs.

Analyses were performed with the use of R statistical software, version 3.1.2 (R Foundation for Statistical Computing, Vienna Austria).

\section{RESULTS}

\section{Baseline Characteristics}

There were 436 patients meeting the enrollment criteria from the 2 centers $(\mathrm{MGH}, \mathrm{n}=192 ; \mathrm{BWH}, \mathrm{n}=244)$. Overall, 78 patients $(17.9 \%)$ were IVDUs currently engaging in IV drug use with the proportion significantly increasing during the study period $(P=.048)$ (Figure 1$)$, particularly after $2012(14.8 \%-26.1 \% ; P=.006)$. Documented drugs of use included heroin only in 33, cocaine only in 18 , combined heroin and cocaine in 19 , heroin or cocaine combined with other IV drugs in 5, amphetamine in 2 and polysubstance in 1 with others unknown.

The baseline profiles of patients according to current IV drug use status are summarized in Table 1. Overall, compared with non-IVDUs, IVDUs were younger and had fewer cardiovascular risk factors (eg, diabetes, hypertension, renal dysfunction, and European System for Cardiac Operative Risk Evaluation II score). They presented more frequently; however, with current cigarette smoking, embolic events, large vegetations, and right-sided and multiple valvular involvement. There were no significant
TABLE 1. Baseline characteristics between intravenous drug users (IVDUs) and non-IVDUs

\begin{tabular}{|c|c|c|c|}
\hline & $\begin{array}{c}\text { IVDU } \\
(\mathbf{n}=78)\end{array}$ & $\begin{array}{c}\text { Non-IVDU } \\
(\mathbf{n}=\mathbf{3 5 8})\end{array}$ & $\begin{array}{c}P \\
\text { value }\end{array}$ \\
\hline Age (y) & $35.9 \pm 9.9$ & $59.3 \pm 14.1$ & $<.001$ \\
\hline Female gender & $30(38.5)$ & $111(31.0)$ & .20 \\
\hline Body mass index & $26.7 \pm 7.9$ & $27.8 \pm 7.0$ & .24 \\
\hline Ethnicity & & & .83 \\
\hline White & $68(87.2)$ & $319(89.1)$ & \\
\hline Black & $5(6.4)$ & $14(3.9)$ & \\
\hline Hispanic & $1(1.3)$ & $9(2.5)$ & \\
\hline Asian & $1(1.3)$ & $5(1.4)$ & \\
\hline Other & $3(3.8)$ & $11(3.1)$ & \\
\hline Diabetes mellitus & $6(7.6)$ & $74(20.7)$ & .027 \\
\hline Hypertension & $16(20.5)$ & $225(62.8)$ & $<.001$ \\
\hline Cigarette smoking history & $53(67.9)$ & $142(39.7)$ & $<.001$ \\
\hline Current cigarette smoking & $28(35.9)$ & $29(8.1)$ & $<.001$ \\
\hline $\begin{array}{l}\text { New York Heart Association } \\
\text { functional class III or IV }\end{array}$ & $35(44.9)$ & $177(49.4)$ & .46 \\
\hline On dialysis & $3(3.8)$ & $31(8.7)$ & .24 \\
\hline $\begin{array}{l}\text { Creatinine clearance, } \\
\mathrm{mL} / \mathrm{min} / 1.73 \mathrm{~m}^{2}\end{array}$ & $103.5 \pm 53.6$ & $73.1 \pm 44.1$ & $<.001$ \\
\hline Embolic events & $36(46.2)$ & $107(29.9)$ & .006 \\
\hline Cerebral & $21(26.9)$ & $93(26.0)$ & .86 \\
\hline Peripheral & 15 & 14 & \\
\hline Causative pathogens & & & .14 \\
\hline Viridans group streptococci & $16(20.5)$ & $89(24.9)$ & \\
\hline Other streptococci & $2(2.6)$ & $33(9.2)$ & \\
\hline Staphylococcus aureus & $30(38.5)$ & $97(27.1)$ & \\
\hline Methicillin-resistant & $9(11.5)$ & $30(8.4)$ & \\
\hline $\begin{array}{l}\text { Staphylococci, } \\
\text { coagulase-negative }\end{array}$ & $10(12.8)$ & $65(18.2)$ & \\
\hline Methicillin-resistant & $1(1.3)$ & $35(9.8)$ & \\
\hline Entercococci & $12(15.4)$ & $48(13.4)$ & \\
\hline Others & $9(11.5)$ & $24(6.7)$ & \\
\hline Negative culture & $9(11.5)$ & $25(7.0)$ & \\
\hline Single valve affected & $57(73.1)$ & $294(82.1)$ & \\
\hline Aortic valve & $32(41.0)$ & $200(55.9)$ & \\
\hline Mitral valve & $13(16.7)$ & $86(24.0)$ & \\
\hline Tricuspid valve & $12(15.4)$ & $8(2.2)$ & \\
\hline Multiple valves affected & $21(26.9)$ & $64(17.9)$ & .068 \\
\hline Aortic + mitral & $13(16.7)$ & $54(15.1)$ & \\
\hline Aortic + tricuspid & $3(3.8)$ & $6(1.7)$ & \\
\hline Mitral + tricuspid & $5(6.4)$ & $2(0.6)$ & \\
\hline Aortic + mitral + tricuspid & 0 & $2(0.6)$ & \\
\hline Right-side valve involvement & $20(25.6)$ & $18(5.0)$ & $<.001$ \\
\hline Vegetation diameter $\geq 10 \mathrm{~mm}$ & $55(70.5)$ & $178(49.7)$ & $<.001$ \\
\hline Abscess formation & $18(23.1)$ & $121(33.8)$ & .066 \\
\hline Prosthetic endocarditis & $17(21.8)$ & $110(30.7)$ & .12 \\
\hline $\begin{array}{l}\text { Severe dysfunction of } \\
\text { affected valves }\end{array}$ & $59(75.6)$ & $245(68.4)$ & .21 \\
\hline $\begin{array}{l}\text { Left ventricular ejection } \\
\text { fraction }(\%)\end{array}$ & $59.5 \pm 10.4$ & $60.1 \pm 10.9$ & .64 \\
\hline $\begin{array}{l}\text { European system for cardiac } \\
\text { operative risk } \\
\text { evaluation II score }\end{array}$ & $\begin{array}{r}9.5 \pm 8.3 \\
(1.8-42.0)\end{array}$ & $\begin{array}{c}13.4 \pm 12.6 \\
(1.8-82.9)\end{array}$ & .001 \\
\hline
\end{tabular}

Values are presented as mean \pm standard deviation, $\mathrm{n}(\%)$, or $\% \pm$ standard deviation (range). IVDU, Intravenous drug users. 
TABLE 2. Surgical profiles

\begin{tabular}{|c|c|c|c|}
\hline & $\begin{array}{c}\text { IVDU } \\
(\mathbf{n}=\mathbf{7 8})\end{array}$ & $\begin{array}{l}\text { Non- IVDU } \\
(\mathbf{n}=\mathbf{3 5 8})\end{array}$ & $\begin{array}{c}P \\
\text { value }\end{array}$ \\
\hline $\begin{array}{l}\text { Interval from admission } \\
\text { to surgery (d) }\end{array}$ & $7(0-76)$ & $6(0-140)$ & .098 \\
\hline Emergent surgery & $16(20.5)$ & 83 (23.2) & .61 \\
\hline On IABP & $3(3.8)$ & $18(5.0)$ & $>.99$ \\
\hline Primary procedure & & & .87 \\
\hline Valve repair & $10(12.8)$ & $35(9.8)$ & \\
\hline $\begin{array}{l}\text { Valve replacement, } \\
\text { mechanical }\end{array}$ & $18(23.1)$ & $81(22.6)$ & \\
\hline $\begin{array}{l}\text { Valve replacement, } \\
\text { bioprostheses }\end{array}$ & $35(44.9)$ & $171(47.8)$ & \\
\hline Valve replacement, allograft & $15(19.2)$ & $71(19.8)$ & \\
\hline \multicolumn{4}{|l|}{ Associated procedures } \\
\hline Ascending aorta replacement & $2(2.6)$ & $20(5.6)$ & .27 \\
\hline CABG & $10(12.8)$ & $56(15.6)$ & .60 \\
\hline Aortic root replacement & $19(24.4)$ & $96(26.8)$ & .78 \\
\hline $\begin{array}{l}\text { Cardiopulmonary bypass } \\
\text { time ( } \mathrm{min})\end{array}$ & $191.3 \pm 103.8$ & $215.5 \pm 142.0$ & .34 \\
\hline Cardiac ischemic time (min) & $145.9 \pm 85.3$ & $159.3 \pm 97.8$ & .30 \\
\hline
\end{tabular}

differences in gender and race/ethnicity. Causative pathogens, including the rates of methicillin-resistant Staphylococcus aureus infection were similar $(11.5 \%$ in IVDUs [9 out of 78] and $8.4 \%$ in non-IVDUs [30 out of 358 ]; $P=.38$ ) between the 2 groups.

Surgical profiles of patients are detailed in Table 2. Overall, 99 patients $(22.7 \%)$ underwent emergent surgery and 21 patients $(4.8 \%)$ had intra-aortic balloon pumps placed before surgery. Valves were repaired in 45 patients $(10.3 \%)$. Replacements were with mechanical prostheses in 99 patients $(22.7 \%)$, bioprostheses in 206 patients $(47.2 \%)$, or human allografts (homografts) in 86 patients $(19.7 \%)$. There were no significant differences between

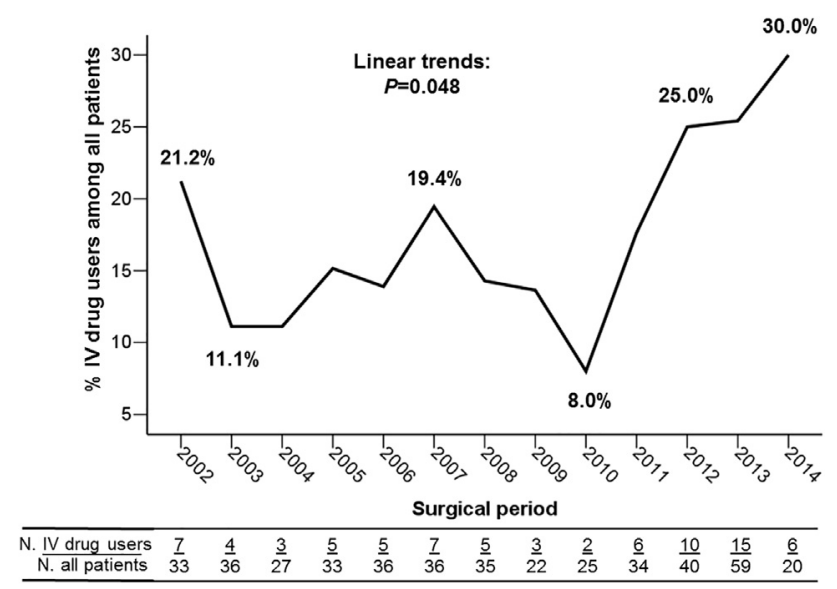

FIGURE 1. Trends in proportions of intravenous (IV) drug users among surgical patients with infective endocarditis over time.
IVDUs and non-IVDUs in operative profiles. All patients received at least 4 to 6 weeks of IV antibiotic therapy regardless of IV drug use status.

\section{Outcome: Overall Cohort}

Thirty-day mortality rates were lower in IVDUs than non-IVDUs ( $3.8 \%$ vs $13.7 \% ; P=.012)$.

Late follow-up data derived from the Partners database were complete in $76.4 \%$ of the entire cohort with a median duration of 29.4 months (quartile 1-3, 570 patient-years). Completeness of follow-up was lower in IVDUs than in the non-IVDU group $(73.5 \%$ vs $77.1 \%)$, but without statistical significance $(P=.096)$. Major adverse events for the entire cohort in the form of valve-related complications were known to occur in 69 patients, including recurrence of IE in 42 patients, valve reoperation in 35 patients, thromboembolism in 17 patients, and anticoagulation-related hemorrhage in 16 patients (Table 3). Kaplan-Meier curves did not show a significant difference in overall survival rates between IVDUs and non-IVDUs; however, freedom from valve-related complications were significantly lower among IVDUs, mainly attributed to higher rates of reinfection and reoperation compared with non-IVDUs (Figure 2).

Overall 5- and 10-year survival rates were $78.9 \% \pm 6.0 \%$ and $69.5 \% \pm 8.3 \%$ in IVDUs, respectively; and $76.1 \% \pm 2.6 \%$ and $68.7 \% \pm 3.9 \%$ in non-IVDUs, respectively $(P=.39)$. When adjusted by propensity score, IVDUs tended to have lower risk of early mortality (HR, 0.32 ; $95 \%$ CI, $0.08-1.36 ; P=.13$ for 90 -day death) but with higher risk of late mortality (HR, 2.07; 95\% CI, $0.78-5.48 ; P=.14$ ) compared with non-IVDUs; however, they were statistically insignificant.

Five- and 10-year-survival rates free of valve-related events were $40.9 \% \pm 7.5 \%$ and $6.9 \% \pm 6.2 \%$ among IVDUs, respectively; and $63.9 \% \pm 3.3 \%$ and $50.8 \% \pm 4.9 \%$ in non-IVDUs $(P=.006)$. After propensity score adjustments, risks of valve-related complications were significantly higher in IVDUs compared with non-IVDUs (HR, 3.82; 95\% CI, 1.95-7.49; $P<.001$ ), which mainly stemmed from a higher risk of reinfection and consequent reoperations (Table 3).

\section{Outcomes: IVDU Subgroup}

Among early IVDU IE survivors $(\mathrm{n}=75), 28$ patients $(37.3 \%)$ had known reinfection of the valves at a median of 18.1 months (range, 0.2-54.3 months) following valve surgery. Among these, $1(3.6 \%)$ occurred within 30 days, $9(32.1 \%)$ occurred between 30 days and 1 year, and 18 $(64.3 \%)$ occurred more than 1 year after surgery. Causative organisms of the reinfections were viridans group streptococci in 6 patients $(21.4 \%)$, methicillin-susceptible staphylococci in 5 patients $(17.9 \%)$, methicillin-resistant staphylococci in 4 patients $(14.3 \%)$, enterococci in 2 
TABLE 3. Unadjusted and adjusted clinical outcomes according to current status of intravenous drug users (IVDUs)

\begin{tabular}{|c|c|c|c|c|c|c|c|c|}
\hline & \multicolumn{2}{|c|}{ No. of events } & \multicolumn{3}{|c|}{ Crude } & \multicolumn{3}{|c|}{ Propensity-adjusted } \\
\hline & IVDU & Non-IVDU & Hazard ratio & $\begin{array}{c}95 \% \text { Confidence } \\
\text { interval }\end{array}$ & $P$ value & Hazard ratio & $\begin{array}{c}95 \% \text { Confidence } \\
\text { interval } \\
\end{array}$ & $P$ value \\
\hline 30-d mortality & 1 & 40 & 0.10 & 0.01-0.48 & .026 & 0.15 & 0.01-1.01 & .10 \\
\hline 90-d mortality & 3 & 49 & 0.25 & $0.06-0.71$ & .024 & 0.32 & $0.08-1.36$ & .13 \\
\hline Late ( $>90 \mathrm{~d})$ mortality & 10 & 30 & 1.32 & $0.66-2.63$ & .45 & 2.07 & $0.78-5.48$ & .14 \\
\hline Valve-related complications & 32 & 37 & 4.07 & $2.53-6.55$ & .001 & 3.82 & $1.95-7.49$ & $<.001$ \\
\hline Valve reinfection & 28 & 14 & 9.28 & $4.87-17.68$ & $<.001$ & 6.20 & $2.56-15.00$ & $<.001$ \\
\hline Valve reoperation & 18 & 17 & 5.03 & $2.58-9.82$ & .005 & 3.66 & 1.44-9.30 & .006 \\
\hline Thromboembolism & 7 & 10 & 2.92 & $1.11-7.68$ & .030 & 2.54 & $0.62-10.47$ & .20 \\
\hline Hemorrhage & 5 & 11 & 1.75 & $0.60-5.05$ & .30 & 4.33 & 1.03-18.17 & .045 \\
\hline
\end{tabular}

$I V D U$, Intravenous drug user.

patients $(7.1 \%)$, and fungus in 2 patients $(7.1 \%)$, whereas 9 patients $(32.1 \%)$ showed culture-negative results. Overall, only 6 patients $(21.4 \%)$ were found to have the same causative organisms as at initial presentation.

Of the 28 patients with reinfection, 14 underwent surgery and 14 were treated with antimicrobial therapy only. The reasons for medical therapy in the latter 14 patients were presence of intracranial hemorrhage in 3 patients
(31.4\%), prohibitive surgical risk due to severity of illness in 2 patients $(14.3 \%)$, active in-hospital use of IV drugs in 3 patients $(31.4 \%)$, and cardiac arrest during preparation for operation in 1 patient $(7.1 \%)$. Another 5 patients $(35.7 \%)$ were successfully treated medically with complete resolution of IE. Among those treated surgically there were no early surgical deaths, although 1 patient died of intracranial hemorrhage at 46.7 months postoperation. The median
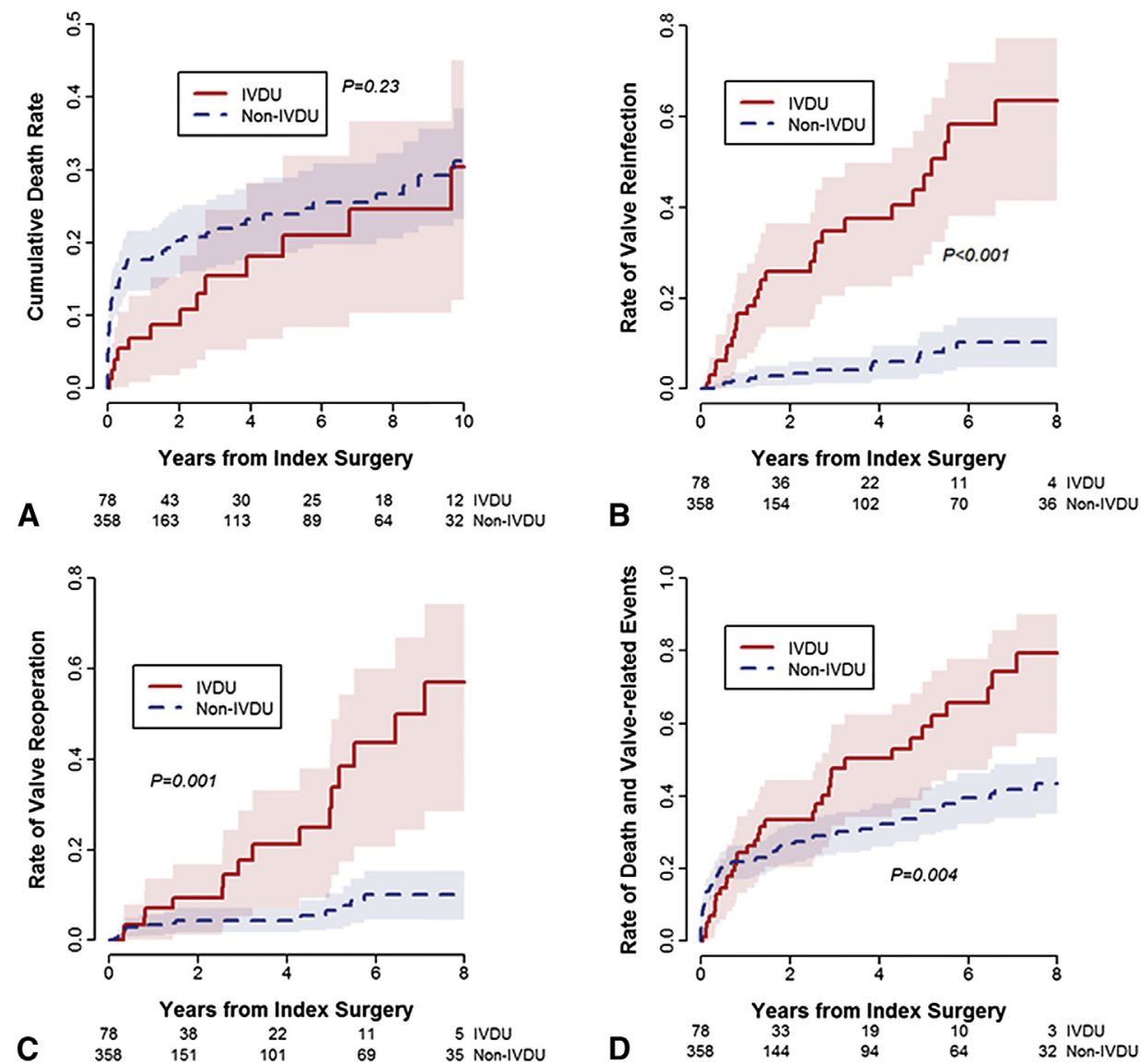

FIGURE 2. Kaplan-Meier curves for clinical outcomes between intravenous drug users (IVDUs) and non-IVDUs. A, Overall death. B, Valve reinfection. C, Valve reoperation. D, Composite of valve-related complications. Transparent bands indicate area within the $95 \%$ confidence interval. 


\section{Degree of contamination}

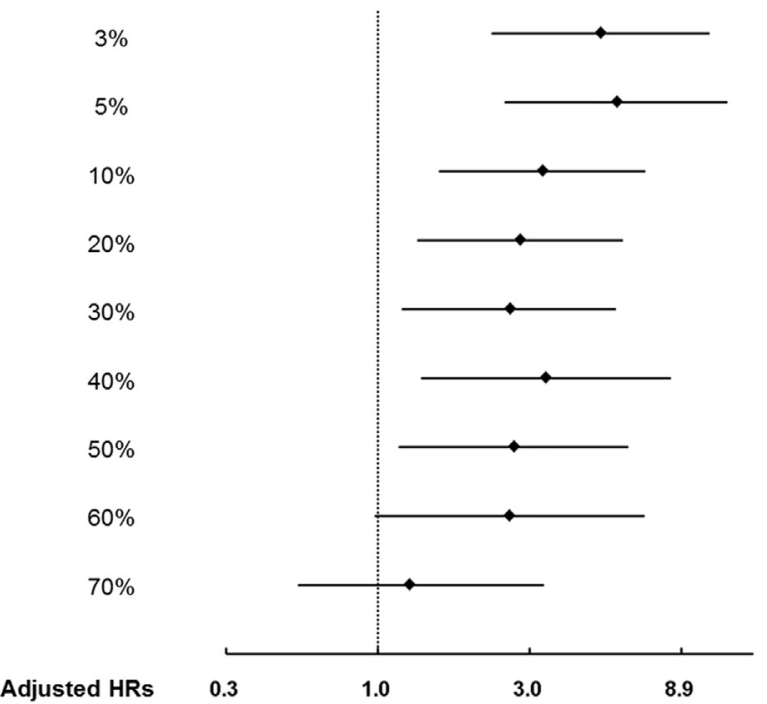

FIGURE 3. Effects of reclassification of patients who were nonintravenous drug users to intravenous drug users on hazard ratios (HRs) for the risk of reinfection. Dots and horizontal lines indicate HRs and $95 \%$ confidence intervals, respectively.

duration of antimicrobial therapy in the 14 patients who had only medical therapy was 6.0 weeks (range, $3-12$ weeks) with 3 in-hospital deaths $(21.4 \%)$ and 3 late deaths $(21.4 \%)$. Causes of the early deaths were sepsis in 2 patients and ventricular arrhythmia in 1 patient, and the causes of late deaths were repeated recurrence of IE in 2 patients and sudden death in 1 patient. The 5-year survival rates among surgical and medical therapy patients for recurrent IE in IVDUs were $91.7 \% \pm 8.0 \%$ and $38.9 \% \pm 16.7 \%$, respectively $(P=.066)$ (Figure E1). Reoperative valve operations were undertaken for reasons other than reinfection in 6 other patients $(7.7 \%)$ for insufficiency of a repaired valve $(n=2)$ or structural deterioration of a prosthetic valve (homograft $[n=3]$ or xenograft bioprostheses $[n=1])$.

Overall, 11 late deaths $(14.1 \%)$ occurred in IVDUs. Causes of deaths were recurrence of IE in 6 patients, intracranial hemorrhage in 1 patient, and metastatic lung cancer in 1 patient, whereas causes could not be specified in 3 patients: 1 died suddenly and 2 died of unknown causes, whereas 1 was found dead while actively using heroin.

\section{Sensitivity Analysis}

Because of the challenges associated with determining with certainty the IV drug use status of all patients in the study, we undertook a sensitivity analysis of the influence of misclassification, as illustrated in Figure 3. The forest plots indicate adjusted HRs for valve reinfection according to the increasing proportion of reclassified patients from non-IVDUs to IVDUs (3\%$70 \%$ ). For valve reinfection, significantly increased risks are observed up to $50 \%$, whereas the proportion of reclassification that would be required to account for the observed increased risk of reinfection would be at least $60 \%$.

\section{DISCUSSION}

Our study confirms an increase in the proportion of IVDUs amongst surgical patients with active IE, almost doubling during the study interval. This is consistent both with our clinical impression and the virtual epidemic of increasing IV drug use in the general population as reported by the Centers for Disease Control and Prevention. ${ }^{1}$ Perhaps more unexpectedly to us, the data also showed a markedly lower operative risk among IVDUs than non-IVDUs. This is likely in part because the former were typically 25 years younger and had fewer comorbidities compared with the non-IVDUs. Another potential factor may be surgical selection bias, because we did not capture all patients seen with IE and cannot therefore account for those who were not accepted for surgical intervention. It is possible that a subset of extremely ill individuals were not offered surgery.

Despite superior early survival, late outcomes when corrected for age and other factors by propensity score were worse for IVDUs than non-IVDUs, with higher rates of reinfection and reoperation. This is likely a reflection of the challenge of recidivism among IVDUs, although actual data concerning recurrent drug use are hard to come by. Individuals may well not be forthright in responding to this sensitive question when presenting with IE after valve surgery for IVDU-related IE out of concern that this will influence the enthusiasm of clinicians to reoperation once again. The same may be true of family members. Furthermore, unless a drug screen returns positive, the responses cannot be readily verified.

Our findings of a rising incidence of IV drug use-associated IE are consistent with a recent Swedish nationwide cohort study of 7603 patients with IE, 990 of whom were treated surgically. ${ }^{6}$ In that study, the 30 -day mortality remained constant at around $10 \%$ across the decade of the study, indicating that despite general medical progress in the current era, IE remains a highly lethal condition. Overall, in contrast to our study, the absolute mortality at 5 years' follow-up was lower for the 355 IVDUs than for non-IVDUs, when compared with ageand gender-matched general population; however, IVDUs showed a standardized mortality ratio of $19.1(95 \% \mathrm{CI}$, 13.5-27.1), which was much higher than other subgroups (standardized mortality ratio range, 1.8-6.3). Similarly, Rabkin and colleagues $^{17}$ observed markedly lower long-term survival among IVDUs than non-IVDUs and, 
conversely, less frequent reinfection. The reasons for this difference is a matter of speculation; however, it is clear that the socioeconomic aspects of IV drug use are rapidly changing in this country, with heroin use markedly up among the middle class or wealthy. ${ }^{29}$ This may translate into greater access to health care should use recur. It should be noted that this disappointing long-term survival of IV drug use has been demonstrated independent of IE. Many IV drug initiators become chronic users, and survival is significantly compromised should they not resolve IV drug use. ${ }^{30-33}$ The mortality rate among long-term IV drug use has been shown to be 6.9 times greater than the general population with an average loss of life of 18.3 years. ${ }^{30,32}$ Although 1 study indicated IE as the most common cause of death among IVDUs, ${ }^{31}$ other studies showed drug overdose, accident, violence, and other chronic disease such as AIDS and liver cirrhosis as competing leading causes of death in these individuals. $30,32-34$

The combination of anticipated short life expectancy despite young chronologic age and the perceived high risks of treatment failure and recurrence of the disease after surgery challenge many front-line health care providers as an ethical controversy. ${ }^{16,20}$ Despite the growing incidence of IV drug use, current practice guidelines do not address surgical indications or management strategies for active IVDUs specifically and treating physicians are left to formulate therapeutic plans on an individual basis without much hard evidence in the literature. The results of this present study help to fill that evidence gap. These data suggest that for IVDUs actively injecting, the technical exercise of replacing the infected valve(s) combined with antimicrobial therapy can be performed at low perioperative risk, but may be incomplete therapy without the addition of effective addiction treatment. It is apparent that resolution or minimization of postoperative IV drug use would likely improve outcomes for this population via prevention of late reinfection just as discontinuation of tobacco use may improve outcomes after coronary revascularization. From a surgical standpoint, failure to resolve IV drug use is comparable to leaving the nidus of infection behind, as shown by a 10 -year event-free survival rate of only $6.9 \% \pm 6.2 \%$ among IVDUs. Given the very high recidivism rate of IVDUs, insistence by treating clinicians on agreement by the subject to participation in a drug rehabilitation program might be a reasonable consideration. Consultation to institutional ethics committee may also be appropriate when making a decision to undertake surgery in active IVDUs who refuse to enter a drug rehabilitation program and are likely to remain at high risk to reinfect their valve. In 1 of our institutions (MGH) consultation with an addiction counselor has become standard routine at the time of surgical consultation for IE in IVDUs.
Finally, we observed Staphylococcus aureus as the most common pathogen of IE among IVDUs and right-side valve involvement to be more common in IVDUs than non-IVDUs, as has been reported previously. ${ }^{35-37}$ Unlike earlier prior reports we found left-sided valve involvement predominant among IVDUs who undergo surgery. ${ }^{37}$ This is consistent with the findings of Rabkin and colleague ${ }^{17}$ and may be a reflection of a shift in surgical philosophy away from intervention on right-sided lesions in favor of antimicrobial therapy and the implantation of a prosthetic makes any subsequent infection an even more complicated problem. The poor late outcomes in IVDUs could not be attributed to differences in the virulence or type of organism.

\section{Limitations}

This study has inherent limitations in the retrospective nature of the research. Study subjects are affected by surgical selection bias because only patients accepted for surgery were included and those who received medical therapy only were not, nor was there a medicaltreatment-only control group for comparison. Obtaining reliable follow-up data concerning reinfection and valverelated complications in this patient population was also challenging. Because this group is the most challenging in follow-up, the data are likely biased in favor of lower event rates in this subgroup. Finally, the data set represents the experience of urban tertiary academic referral centers, and therefore it is subject to referral bias from the community.

\section{CONCLUSIONS}

The proportion of IVDU among surgical patients with IE is increasing. Although IVDUs are younger, with lower baseline cardiovascular risk burdens, long-term clinical outcomes are discouraging with a significant rate of reinfection and a trend toward higher risk of late mortality. These data highlight the need to aggressively address the expanding drug use epidemic that is driving the increased rate of IE in this population and provide effective addiction treatment postoperatively to prevent reinfection.

\section{Webcast}

You can watch a Webcast of this AATS meeting presentation by going to: http://webcast.aats.org/2015/Video/ Tuesday/04-28-15_4E_1655_Kim.mp4.

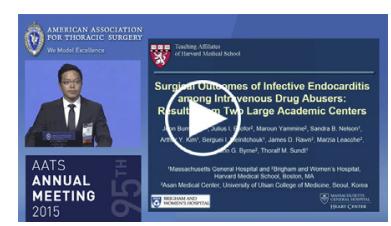




\section{Conflict of Interest Statement}

Dr Thoralf M. Sundt is a consultant for Thrasos Therapeutics. All other authors have nothing to disclose with regard to commercial support.

\section{References}

1. Substance Abuse and Mental Health Services Administration. Results from the 2013 National Survey on Drug Use and Health: Summary of national findings. Rockville: Substance Abuse and Mental Health Services Administration; 2014. NSDUH Series H-48, HHS Publication No. SMA 14-4863.

2. Hooten WM, Bruce BK. Beliefs and attitudes about prescribing opioids among healthcare providers seeking continuing medical education. J Opioid Manag. 2011;7:417-24

3. Slevin KA, Ashburn MA. Primary care physician opinion survey on FDA opioid risk evaluation and mitigation strategies. J Opioid Manag. 2011;7: 109-15.

4. Centers for Disease Control and Prevention. Trends in drug-poisoning deaths involving opioid analgesics and heroin: United States, 1999-2012. Available at: http://www.cdc.gov/nchs/data/hestat/drug_poisoning/drug_poisoning.htm. Accessed March 22, 2016

5. Chu VH, Park LP, Athan E, Delahaye F, Freiberger T, Lamas C, et al. Association between surgical indications, operative risk, and clinical outcome in infective endocarditis: a prospective study from the international collaboration on endocarditis. Circulation. 2015;131:131-40.

6. Ternhag A, Cederstrom A, Torner A, Westling K. A nationwide cohort study of mortality risk and long-term prognosis in infective endocarditis in Sweden. PLoS One. 2013;8:e67519.

7. Nishimura RA, Otto CM, Bonow RO, Carabello BA, Erwin JP III, Guyton RA, et al. 2014 AHA/ACC Guideline for the Management of Patients With Valvular Heart Disease: a report of the American College of Cardiology/ American Heart Association Task Force on Practice Guidelines. Circulation. 2014:129:e521-643.

8. Shih CJ, Chu H, Chao PW, Lee YJ, Kuo SC, Li SY, et al. Long-term clinical outcome of major adverse cardiac events in survivors of infective endocarditis: a nationwide population-based study. Circulation. 2014;130: 1684-91.

9. Grubitzsch H, Schaefer A, Melzer C, Wernecke KD, Gabbieri D, Konertz W. Outcome after surgery for prosthetic valve endocarditis and the impact of preoperative treatment. J Thorac Cardiovasc Surg. 2014;148:2052-9.

10. Lytle BW, Sabik JF, Blackstone EH, Svensson LG, Pettersson GB, Cosgrove DM III. Reoperative cryopreserved root and ascending aorta replacement for acute aortic prosthetic valve endocarditis. Ann Thorac Surg. 2002; 74:S1754-7.

11. Meszaros K, Nujic S, Sodeck GH, Englberger L, König T, Schönhoff F, et al. Long-term results after operations for active infective endocarditis in native and prosthetic valves. Ann Thorac Surg. 2012;94:1204-10.

12. Musci M, Weng Y, Hubler M, Amiri A, Pasic M, Kosky S, et al. Homograft aortic root replacement in native or prosthetic active infective endocarditis: twenty-year single-center experience. J Thorac Cardiovasc Surg. 2010;139: 665-73.

13. Berlin JA, Abrutyn E, Strom BL, Kinman JL, Levison ME, Korzeniowski OM, et al. Incidence of infective endocarditis in the Delaware Valley, 1988-1990. Am J Cardiol. 1995;76:933-6.

14. Hogevik H, Olaison L, Andersson R, Lindberg J, Alestig K. Epidemiologic aspects of infective endocarditis in an urban population. A 5-year prospective study. Medicine (Baltimore). 1995;74:324-39.

15. Spijkerman IJ, van Ameijden EJ, Mientjes GH, Coutinho RA, van den Hoek A. Human immunodeficiency virus infection and other risk factors for skin abscesses and endocarditis among injection drug users. J Clin Epidemiol. 1996:49:1149-54.

16. DiMaio JM, Salerno TA, Bernstein R, Araujo K, Ricci M, Sade RM. Ethical obligation of surgeons to noncompliant patients: can a surgeon refuse to operate on an intravenous drug-abusing patient with recurrent aortic valve prosthesis infection? Ann Thorac Surg. 2009;88:1-8.
17. Rabkin DG, Mokadam NA, Miller DW, Goetz RR, Verrier ED, Aldea GS. Long-term outcome for the surgical treatment of infective endocarditis with a focus on intravenous drug users. Ann Thorac Surg. 2012:93:51-7.

18. Thalme A, Westling K, Julander I. In-hospital and long-term mortality in infective endocarditis in injecting drug users compared to non-drug users: a retrospective study of 192 episodes. Scand J Infect Dis. 2007;39: 197-204.

19. Hubbell G, Cheitlin MD, Rapaport E. Presentation, management, and followup evaluation of infective endocarditis in drug addicts. Am Heart J. 1981; 102:85-94.

20. Hull SC, Jadbabaie F. When is enough enough? The dilemma of valve replacement in a recidivist intravenous drug user. Ann Thorac Surg. 2014;97: 1486-7.

21. Dawood MY, Cheema FH, Ghoreishi M, Foster NW, Villanueva RM, Salenger R, et al. Contemporary outcomes of operations for tricuspid valve infective endocarditis. Ann Thorac Surg. 2015;99:539-46.

22. The Society of Thoracic Surgeons. Online STS adult cardiac surgery risk calculator. Available at: http://riskcalc.sts.org/stswebriskcalc/\#/. Accessed March 21, 2016

23. Mathers BM, Degenhardt L, Phillips B, Wiessing L, Hickman M, Strathdee SA et al. Global epidemiology of injecting drug use and HIV among people who inject drugs: a systematic review. Lancet. 2008;372:1733-45.

24. Murphy SN, Chueh HC. A security architecture for query tools used to access large biomedical databases. Proc AMIA Symp. 2002;552-6. Available at https://aspe.hhs.gov. Accessed March 21, 2016.

25. Conrad MF, Michalczyk MJ, Opalacz A, Patel VI, LaMuraglia GM, Cambria RP The natural history of asymptomatic severe carotid artery stenosis. J Vasc Surg. 2014;60:1218-25.

26. Horkan CM, Purtle SW, Mendu ML, Moromizato T, Gibbons FK, Christopher KB. The association of acute kidney injury in the critically ill and postdischarge outcomes: a cohort study. Crit Care Med. 2015;43: 354-64.

27. Akins CW, Miller DC, Turina MI, et al. Guidelines for reporting mortality and morbidity after cardiac valve interventions. J Thorac Cardiovasc Surg. 2008; $135: 732-8$.

28. Therneau TM, Grambsch PM. Modeling survival data: extending the Cox model. New York: Springer; 2000.

29. The numbers behind America's heroin epidemic. Available at: http://www nytimes.com/interactive/2015/10/30/us/31 heroin-deaths.html?_r=0. Accessed January 17, 2016.

30. Joe GW, Simpson DD. Mortality rates among opioid addicts in a longitudinal study. Am J Public Health. 1987;77:347-8.

31. Perucci CA, Forastiere F, Rapiti E, Davoli M, Abeni DD. The impact of intravenous drug use on mortality of young adults in Rome, Italy. Br J Addict. 1992;87:1637-41.

32. Smyth B, Fan J, Hser YI. Life expectancy and productivity loss among narcotics addicts thirty-three years after index treatment. J Addict Dis. 2006;25: 37-47.

33. Smyth B, Hoffman V, Fan J, Hser YI. Years of potential life lost among heroin addicts 33 years after treatment. Prev Med. 2007:44:369-74.

34. Office of the Assistant Secretary for Planning and Evaluation. DAWN 2003: Area profiles of drug-related mortality. Office of Applied Studies, SAMHSA. Drug Abuse Warning Network 2003 (09/2004 update). Available at: https://aspe.hhs. gov. Accessed March 21, 2016.

35. DiNubile MJ. Abbreviated therapy for right-sided Staphylococcus aureus endocarditis in injecting drug users: the time has come? Eur J Clin Microbiol Infect Dis. 1994;13:533-4.

36. Hecht SR, Berger M. Right-sided endocarditis in intravenous drug users Prognostic features in 102 episodes. Ann Intern Med. 1992;117:560-6.

37. Mathew J, Addai T, Anand A, Morrobel A, Maheshwari P, Freels S. Clinical features, site of involvement, bacteriologic findings, and outcome of infective endocarditis in intravenous drug users. Arch Intern Med. 1995; $155: 1641-8$

Key Words: intravenous drug use, infective endocarditis, valvular heart disease, operative risk 


\section{Discussion}

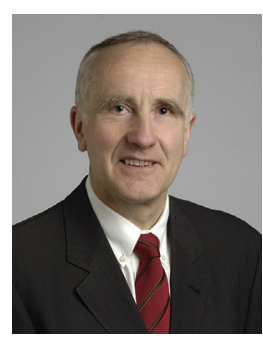

Dr Gosta B. Pettersson (Cleveland, Ohio). I would like to thank the Association for the honor to discuss this important article related to this epidemic of drug abuse. Thank you and congratulations on a nice presentation and for providing the article in a timely fashion.

This article addresses 1 important complication of drug abuse: drug abuse presently accounts for more than a quarter of all surgical endocarditis cases at Mass General and Brigham and Women's Hospital in Boston. This is a scary trend, and in their introduction the authors question the utility of aggressive resource-intensive surgical procedures for these patients. This is a moral, ethical, and medical dilemma. Moral and ethical if we look upon drug abuse as a self-inflicted problem and medical if we look at drug abuse as just another comorbidity; for example, comparable to morbid obesity.

The authors clearly show that drug abuse patients, who are younger and have low surgical risk, return with recurrent infection and they do have a decreased late survival, but survival is still $81 \%$ and $72 \%$ at 5 and 10 years, respectively, and we certainly treat many patient groups with worse survival without hesitation.

Although we don't know the exact number, we all believe the majority of the patients return to drug abuse. In this study, 37 patients returned with recurrent endocarditis within 1.5 years, and most of these reinfections were caused by a new organism different from the first, suggesting that they were new injects. We all understand that their long-term outcome is related to our ability to treat their comorbidity more than to our ability to treat their endocarditis-long-term success is all about prevention of continued drug abuse.

At the Cleveland Clinic we have also recognized the drug abuse epidemic, and we have recently reviewed our experience with drug abuse-related endocarditis for the period 2007 to 2012, corresponding to the second half of the study period of Dr Kim's study. Our experience for this 5-year period includes 41 cases, corresponding to $8 \%$ of our total endocarditis patients.

Although our experience is similar to the Boston experience, there are some notable differences between Cleveland and Boston. Heroin was an even more dominating drug in Cleveland than in Boston; $63 \%$ of our patients had tricuspid valve involvement compared with only $25 \%$ of the Boston patients. And more of our patients had Staphylococcus aureus infections: $59 \%$ of ours compared with $38 \%$ in this study.

We also noticed an interesting thing with regard to the risk of death after surgery. The hazard ratio within the first
90 days was lower for the drug abuse patients, but between 90 and 180 days the hazard ratio was actually 9.8 that of nondrug abusers, and then it stabilized at 1.8 , which is very close to your observation.

My first question is related to the follow-up and the reliability of the Social Security Index to confirm vital status and dates of death. This question is relevant to several studies presented during this meeting. On November 1, 2011, some $40 \%$ of the Social Security death master file was deleted from public use by the Congress. According to our understanding, the Social Security Death Index is unlikely to disclose all deaths, and because the data capturing is related to exhausted Social Security benefits rather than death, the Index is more likely to be incomplete for younger patients. Drug abuse patients are younger and notoriously difficult to track.

Are you still convinced that your follow-up with regard to vital status is really that $100 \%$ as you claim or do you agree that we might even have underestimated the number of deaths?

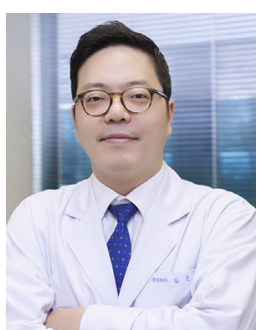

Dr Joon Bum Kim (Boston, Mass). Thank you, Dr Pettersson. Your comment is very important and has to be addressed appropriately.

We have been aware of the potential inaccuracy of the Social Security Death Index in the identification of mortality status; however, this was our best research in our database system, and the Social Security Death Index was searched only if the patient showed missing data on vital status. Fortunately, our Partners Center database has some accurate data on mortality status. So most of the patients were covered by our Partners Center registry, and I remember only 30 patients needed to be looked up in the Social Security Death Index. So I think our data is pretty good in terms of mortality identification.

Dr Pettersson. Do you know what your patients died from? Did they die from drug overdose, endocarditis, or something else?

Dr Kim. Out of 78 intravenous drug abusers, there were 3 early deaths and 11 late deaths, and we could identify the causes of death in 8 patients. They were reinfection in 6 patients, 1 patient died of lung cancer, and 1 died of intracranial hemorrhaging; 3 were unidentified. Of these, 1 found dead while he was using heroin very actively. So we think that 3 patients died from heroin use, but most of our patients died from reinfection among these patients.

Dr Pettersson. My third set of questions relates to our observation that $68 \%$ of our drug addict patients had hepatitis $\mathrm{C}$, a risk not only to the patient but also to the surgical team. Do you know your prevalence of hepatitis $\mathrm{C}$ among your patients? We don't know if some of them 
also have HIV. Do you test for HIV? What extra precautions do you take in the operating room when handling these patients?

Dr Kim. Thank you, Dr Pettersson. I have to acknowledge my ignorance when I began researching this issue and we did not include hepatitis C and HIV data for this work, but at the end of manuscript completion I came to realize that hepatitis $\mathrm{C}$ and HIV are potentially very important to the outcomes.

I believe almost all patients received testing for hepatitis $\mathrm{C}$ and HIV, because these patients are surgical patients. As far as I remember, although I can't present very precise data, hepatitis $\mathrm{C}$ viral infection was more prevalent in these patients-let's say $20 \%$ to $30 \%$ of patients-but I don't remember many patients who had HIV infection among this population.

Dr Pettersson. So my next question is most important. How do you address their fatal disease: Drug addiction? Do you have any conditions for operating on them?

Dr Kim. It is a very challenging question. As far as I believe, the institutional priority of Mass General Hospital is to have some aggressive drug rehabilitation therapy collaborating with other providers of medical care, but I am not sure whether there already are very systematic approaches across the Brigham and Women's and Mass General as well as other individual surgeons' experiences. But I am sure that we need something more than just offering surgical therapy, because we have to eradicate the potential infection sources, let's say, the intravenous drug abusers. So collaborating with the other providers like rehabilitation and psychiatric therapists is very important, I believe.

Dr Pettersson. Do you ever refuse to operate?

Dr Kim. I think there are patients who are refused by physicians, but I am not sure, because our data includes surgical data by more than 15 independent surgeons. So I cannot say the uniform strategy related to those patients.

Dr Pettersson. What do you think about the actual surgical procedure here? What do you do to the tricuspid valve? What do you think about, say, valve replacement in the tricuspid position? What do you think about mechanical valves in these patients? What do you think about pacemaker leads?

Dr Kim. I think the principle of infective endocarditis surgery is complete removal of infection first. If possible, repair would be the best choice whenever amenable. If you can get rid of infection sources and there is some room for repair, I think repair is probably the best choice, especially for the tricuspid position. But if not, we don't hesitate to replace then. Valvulectomy was not our practice across the Brigham and Women's Hospital and Mass General Hospital.

I am not sure whether these drug users are compliant on warfarin therapy, although surgeons had very individualized approaches for every patient whether they can really deal with long-term lifelong warfarin therapy.

Dr Pettersson. Thank you, and once again, congratulations, and congratulations on your excellent defense of your paper.

Dr Kim. Thank you so much. 


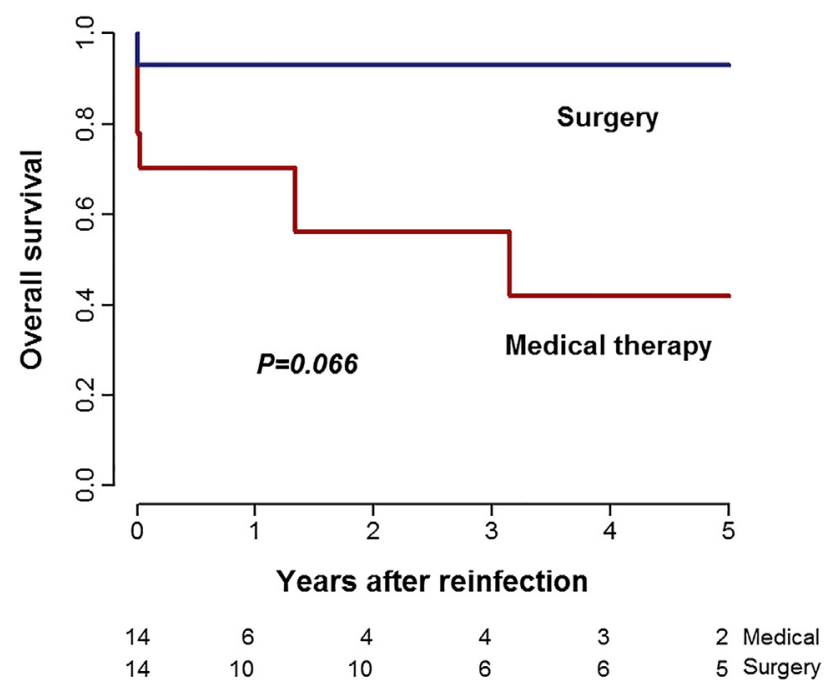

FIGURE E1. Survival after surgical versus medical therapy for recurrence of infective endocarditis in intravenous drug users. 